https://helda.helsinki.fi

Apparent survival, territory turnover and site fidelity rates in Northern Goshawk Accipiter gentilis populations close to the northern range limit

\title{
Tolvanen, Jere
}

2017

Tolvanen, J , Pakanen , V-M , Valkama , J \& Tornberg , R 2017 , ' Apparent survival, territory turnover and site fidelity rates in Northern Goshawk Accipiter gentilis populations close to the northern range limit ' , Bird Study, vol. 64 , no. 2 , pp. 168-177 . https://doi.org/10.1080/00063657.2017.

http://hdl.handle.net/10138/310845

https://doi.org/10.1080/00063657.2017.1309351

unspecified

acceptedVersion

Downloaded from Helda, University of Helsinki institutional repository.

This is an electronic reprint of the original article.

This reprint may differ from the original in pagination and typographic detail.

Please cite the original version. 
1 Apparent survival, territory turnover and site fidelity rates in Northern Goshawk

2 Accipiter gentilis populations close to northern range limit

3

4 Jere Tolvanen ${ }^{1}$, Veli-Matti Pakanen ${ }^{1}$, Jari Valkama ${ }^{2}$ and Risto Tornberg ${ }^{1}$

5

6

$7{ }^{1}$ Department of Ecology and Genetics, University of Oulu, P.O. Box 3000, FI-90014 University of

8 Oulu, Finland.

$9 \quad{ }^{2}$ Finnish Museum of Natural History, P.O. Box 17, FI-00014 University of Helsinki, Finland

12 Short title: Goshawk survival \& site fidelity

Keywords: Capture-mark-recapture, sex-specific apparent survival, breeding dispersal, raptor

16

17

18 Corresponding author:

19 Jere Tolvanen

20 Email: jere.tolvanen@oulu.fi

21 


\section{Summary}

Capsule: Mark-recapture data suggest low apparent survival and sex- and population-specific site fidelity and territory turnover in adult Northern Goshawks Accipiter gentilis breeding in northern Europe.

Aims: Understanding how species cope with global environmental change requires knowledge of variation in population demographic rates, especially from populations close to the species' northern range limit and from keystone species such as raptors. We analyze apparent survival and breeding dispersal propensity of adult Northern Goshawks breeding in northern Europe.

Methods: We used long-term mark-recapture data from two populations in Finland, northern Europe, and Cormack-Jolly-Seber models and binomial GLMs to investigate sex- and populationspecific variation in apparent survival, territory turnover and site fidelity.

Results: We report low apparent survival (53-72\%) of breeding adult goshawks. Breeding dispersal propensity was higher in females than males, especially in northern Finland, contrasting previous studies that suggest high site fidelity in both sexes.

Conclusion: Low apparent survival in females may be mainly due to permanent emigration outside the study areas, whereas in males the survival rate may truly be low. Both demographic aspects may be driven by the combination of sex-specific roles related to breeding and difficult environmental conditions prevailing in northern latitudes during the non-breeding season. 


\section{Introduction}

Populations at the edge of their distribution often face poorer conditions, and consequently suffer from lower rates of reproduction and survival (e.g. Sexton et al. 2009, Karvonen et al. 2012). The ongoing climate change alters environments with particularly pronounced effects being expected at high latitudes and on populations living close to their northern range limit (Jetz et al. 2007, Virkkala et al. 2008). Therefore, studies investigating basic demographic rates in spatially distinct populations close to the species' range limit are highly valuable in understanding the future impacts climate change may have (Gibson et al. 2009, Rehm et al. 2015). Unfortunately, the vast majority of species lack information on different demographic rates that are crucial for understanding population dynamics and population viability (Morris \& Doak 2002). The most urgent need is for information on survival because data for them is rare and survival rates commonly have high elasticity measures implying that even small changes in survival rates may have substantial effects on population demography (Gaillard et al. 2000, Heppell et al. 2000, Saether \& Bakke 2000).

\section{Understanding population dynamics of key species, such as top predators, is particularly important} because they often influence abundance, distribution and behaviour of several other species across trophic levels (Sergio et al. 2008, Lima 2009). For example, raptors have a profound role in animal communities through direct predation on prey populations (Norrdahl \& Korpimäki 2000, Valkama et al. 2005, Park et al. 2008) and indirect effects on the behaviour of prey and other predators (Thomson et al. 2006, Sergio \& Hiraldo 2008, Lima 2009, Morosinotto et al. 2010, Michel et al. 2016), potentially triggering trophic cascades including several trophic levels (Chakarov \& Krüger 2010). So far, research on raptor demography has concentrated on reproduction (e.g. Byholm \& Kekkonen 2008, Björklund et al. 2015), and many raptor species lack even basic estimates of adult survival (Newton et al. 2016), which is unfortunate as the importance of adult survival for 
population growth increases in long-lived species such as raptors (Heppell et al. 2000, Saether \& Bakke 2000, Krüger 2007).

The Northern Goshawk (Accipiter gentilis, hereafter goshawk) is an example of a widely distributed, relatively abundant top predator that has diverse effects on animal communities in boreal forests (Tornberg 2001, Hakkarainen et al. 2004, Mönkkönen et al. 2007, Byholm et al. 2012, Tornberg et al. 2016). However, few studies have concentrated on goshawk demography in Europe or at northern latitudes close to the species' range limit. The survival estimates reported so far are based on ring recoveries (Haukioja \& Haukioja 1970) or radio-telemetry methods (Kenward et al. 1999, Tornberg and Colpaert 2001). Survival and site fidelity estimates derived from markrecapture data are almost absent for European goshawks (but see Krüger 2005). Environmental conditions for goshawks are more difficult in northern latitudes both due to harsher climate (e.g. colder temperature) and lower and more variable food availability (e.g. most prey species migrate south for the winter). Both environmental aspects may affect survival, as has been observed in other northern birds of prey (Brommer et al. 2002, Hakkarainen et al. 2002, Francis \& Saurola 2004). Consequently, survival in northern latitudes may differ from more southern areas, and thus survival estimates from northern populations are valuable in understanding goshawk demography throughout the species range.

We collected mark-recapture data by capturing goshawk adults during the breeding season in two distinct geographical areas in northern Europe, where goshawks breed close ( $c a .400-900 \mathrm{~km})$ to their northern range limit. We estimate apparent adult survival by using open population live recapture models (Cormack-Jolly-Seber models; Lebreton et al. 1992). Because apparent survival is confounded with permanent emigration, we evaluate its impact using time since marking models and by estimating site fidelity and territory turnover rates. 
Materials and methods

92

93

\section{Study species}

Goshawk is a holarctic, territorial, medium-sized raptor showing strong reversed sexual size dimorphism (Kenward 2006). The female incubates and defends the nest during the incubation (from late April to late May in our study areas) and the first half of the nestling period (from late May to late June), while the male is responsible for provisioning food. The female usually takes part in provisioning in the late nestling period (from late June to mid July). Diet consists of small- and medium-sized birds and mammals (Tornberg 1997, Drennan 2006). Typical nesting habitat is mature forest with large trees, high canopy closure and open understories (Penteriani 2002). The residency status of goshawks varies between populations from resident (Boal et al. 2003) to either seasonally (Squires \& Ruggiero 1995) or partially migratory (Kenward et al. 1981, Underwood et al. 2006). In Finland, adult goshawks are usually resident, but may occasionally disperse hundreds of kilometres (R. Tornberg unpubl. radio telemetry data, Saurola et al. 2013). The conservation status of goshawks is 'Near Threatened' in Finland (abundance estimate 8600 individuals; Tiainen et al. 2016) and 'Least Concern' in Europe (332 000-440 000 mature individuals; BirdLife International 2016).

\section{Study areas}

Our study was conducted in two study areas in Finland. The northern study area (hereafter northern Finland, NF) is located around the city of Oulu $\left(65^{\circ} \mathrm{N}, 25^{\circ} \mathrm{E}\right.$; ca. $\left.2200 \mathrm{~km}^{2}\right)$ and consists of coastal lowlands, including the island of Hailuoto in the Baltic sea. The area belongs to the middle boreal vegetation zone. A mosaic of forests and mostly drained bogs covers about two thirds of the area. Forests consist of managed conifer or mixed stands dominated by scots pine (Pinus sylvestris) and 
Norwegian spruce (Picea abies) mixed with deciduous species (Betula sp., Populus tremula).

Agricultural areas and human settlements are concentrated on the coast of the Baltic sea and river valleys.

The southern study area (hereafter southern Finland, SF) consists of two subareas located southeast from the city of Pori $\left(61^{\circ} \mathrm{N}, 22^{\circ} \mathrm{E}\right.$; ca. $\left.2550 \mathrm{~km}^{2}\right)$ and around the city of Turku $\left(61^{\circ} \mathrm{N}, 22^{\circ} \mathrm{E}\right.$; ca. 600 $\mathrm{km}^{2}$ ). The area is also coastal lowland, located in the southern boreal and hemiboreal vegetation zones ca. $500 \mathrm{~km}$ southwest of the NF study area. Landscape is a mixture of forests and agricultural areas. Forests consist of spruce dominated coniferous stands mixed with pine, birches and aspen.

\section{Mark-recapture data}

Breeding goshawk populations have been monitored since 1994 and 1993 in northern and southern Finland, respectively. A territory was defined as a cluster of alternative nest sites and surrounding area used and defended by a goshawk pair (Steenhof \& Newton 2007). All known territories were visited between April and May to determine occupancy. A territory was considered occupied if fresh signs of occupation (prey remains, moulted feathers, faeces etc.) were observed near the nest sites (Steenhof \& Newton 2007). If no signs were found, suitable nearby forest sites were searched for new nest site. Because majority of the forests in our study areas are too young (due to forest management) for goshawk nesting, we used aerial photographs to identify potential new nesting sites and focused our searching efforts on them. This maximized the use of limited resources available for nest searching. The total area of nest search varied depending on the amount of suitable habitat, but usually searching occurred within a kilometre from the old nest site. Nest search was performed by walking slowly within a forest patch in transects ca. $50 \mathrm{~m}$ apart to cover the whole patch while carefully looking for new nest structures or other signs of goshawk activity. We also used playbacks of goshawk vocalizations to locate new breeding pairs and nest sites 
139 (Andersen 2007). Pairs were defined as breeding if at least one egg was laid. Nestlings were ringed 140 at age of $15-30$ days.

Since 1999 in NF and 2002 in SF, breeding adults have been caught at the breeding sites using a raptor net with a mounted eagle owl (Bubo bubo) as a lure. Birds were sexed on the basis of size (Kenward 2006) and marked with individually numbered aluminium leg bands. During the early and late years capture efforts or success were relatively low that could compromise survival estimation. Therefore, we restrict the survival analyses to study periods when capture efforts were highest, i.e. to 2003-2012 in NF and 2005-2011 in SF study area. Survival analysis data sets included 91 individuals and 127 captures in NF and 120 individuals and 163 captures in SF. Site fidelity and territory turnover analyses were based on the full study periods (1999-2016 in NF, 2002-2016 in SF).

\section{Survival analysis}

We used Cormack-Jolly-Seber (CJS) models (Cormack 1964, Jolly 1965, Seber 1965, Lebreton et al. 1992) to estimate apparent survival of breeding adult goshawks. CJS models simultaneously estimate both apparent survival and recapture probability (the probability that a living individual is recaptured/encountered in the study area) and therefore account for temporary emigration of individuals (Lebreton et al. 1992). The resulting survival estimates may nevertheless be confounded with permanent emigration outside the study area, therefore the estimate is termed "apparent survival". Survival analyses included sex (male vs. female) and time since marking (TSM; newly marked individuals vs. individuals marked in previous years; Pradel et al. 1997) as categorical explanatory variables. Since the SF study area consisted of two subareas, the subarea variable 
We kept model structures simple due to small sample sizes. A maximum of three explanatory variables were simultaneously incorporated into a model (two for survival, one for recapture; except for the global models). Interactions and temporal variation were not considered. All explanatory variables were fitted both alone and additively to each of the other variables in the survival model structure. Model structure with constant survival was also applied. Recapture probability model structure included either sex or subarea, or the recapture probability was kept constant. All survival structures were fitted with all different recapture structures, resulting in the total number of 8 and 22 candidate models for the NF and SF data sets, respectively (global models included).

For the NF data, the global model included additive effects of sex and TSM in survival (S) and the effect of sex in recapture (p) model structures $[S(\operatorname{Sex}+\mathrm{TSM}) \mathrm{p}(\mathrm{Sex})]$. For the SF data set the global model included also the additive effect of subarea in both survival and recapture model structures $[\mathrm{S}($ Subarea+Sex+TSM) $\mathrm{p}($ Subarea+Sex $)]$. Goodness of fit testing of the global models and estimation of variance inflation factors $(\widehat{c})$ were done using the parametric bootstrap approach provided in program MARK (White \& Burnham 1999, White et al. 2001). The global models fit both data sets $(\mathrm{NF}: \mathrm{p}=0.202 ; \mathrm{SF}: \mathrm{p}=0.486)$. Slight over-dispersion was corrected for in NF data $(\widehat{c}$ $=1.17)$, but in SF data it was not necessary $(\hat{\mathrm{c}}=1.00)$. Ranking of the candidate models was based on Akaike's Information Criterion corrected for small sample size, and over-dispersion in NF data, (AICc or QAICc; Akaike 1974, Burnham \& Anderson 2002). We quantified the importance of different explanatory variables in explaining the variation in apparent survival and recapture probabilities using the sum of model-specific Akaike weights over all the models that included the specific variable (Burnham \& Anderson 2002). In addition, since some explanatory variables were incorporated in a varying number of models, we also calculated the average Akaike weight for each variable. Apparent survival and recapture probability estimates and associated unconditional 95\% confidence intervals were derived via model averaging over all relevant models (see results for 
details). All survival analyses were performed in program MARK 8.0 (White \& Burnham 1999, White et al. 2001).

\section{Site fidelity and territory turnover}

We calculated site fidelity and turnover rates with two approaches. The first approach included individuals caught in successive years. Site fidelity is the percentage of individuals that stayed on the same territory in successive years, and turnover is the percentage of observations where a breeding individual was replaced by another individual on a territory in successive years. These are the traditional approaches used to estimate site fidelity and territory turnover (see e.g. Bechard et al. 2006, Reynolds \& Joy 2006).

However, estimates based on the traditional approaches may be biased for several reasons. First, if an individual, captured at year $\mathrm{t}$, breeds in the same known territory the next year $(\mathrm{t}+1)$, it is more likely to be recaptured than an individual, which disperses to a new territory, possibly outside the study area or to an unknown territory within the study area. Furthermore, if it is possible to capture individuals only if they are successful in breeding (as is the case in this study) and if breeding success and dispersal propensity are interrelated (e.g. Haas 1998, Hoover 2003, Jiménez-Franco et al. 2013), it may be impossible to capture a dispersing individual in successive years even when the new territory is known. All above-mentioned possibilities support the expectation of obtaining disproportionally more data on site-faithful than on dispersing individuals, i.e. the traditional site fidelity estimates may be biased high. Turnover is based on individuals captured in the same territory, and thus is not biased by dispersal to unknown territories. However, based on our present goshawk data, if a breeding male disappears from its territory, it is rarely replaced immediately by another male. For example in the NF data, in 19 of the 28 cases where the territorial male was replaced, the territory remained unoccupied for at least one year before the new male occupied the 
territory. Therefore, male turnover seldom occurs in successive years, which results in low turnover estimates if the traditional estimation approach is used.

To alleviate the above-mentioned issues we also estimated site fidelity and turnover by including successive captures of individuals (site fidelity), or successive captures within territories (turnover), regardless of the number of years between the captures. These estimates may in turn be biased low (site fidelity) or high (turnover) due to the inclusion of observations with up to nine years between successive captures. The true site fidelity and turnover estimates probably lie somewhere between the two estimates. The estimates of site fidelity and turnover include only one observation per 223 individual/territory.

Generalized linear models (logit link function, binomial error distribution) were used to investigate differences in site fidelity and turnover estimates between males and females in both study areas and between the two study areas within both sexes. Site fidelity and turnover estimates based on both approaches were analysed separately. Statistical significance of the sex or area differences was evaluated by likelihood ratio tests. In the case of the estimates based on the second approach (variable number of years between the captures), the number of years between the captures was included as an additional covariate (centred to the mean; termed 'Years'). The fit of the models to the observed data (overdispersion in binomial models) was assessed by the ratio of residual Development Core Team 2016) was used for the analyses. deviance to the degrees of freedom of the model. If this ratio does not substantially exceed unity, the model with binomial error structure fits well to the data (Collett 2003). Program R 3.3.1 (R 
Apparent adult survival

In northern Finland, apparent survival of breeding adult goshawks was best explained by time since marking (TSM; Tables 1 and 2). However, when comparing the mean Akaike weights of the explanatory variables, a constant survival rate was equally supported as the TSM effect (Table 1). It is unknown whether the individuals, when they were captured for the first time, were also breeding for the first time. However, of the territories where an individual was captured for the first time, $79 \%$ had contained breeding pairs for one year at the most before their capture indicating that most of the individuals captured for the first time were also breeding for their first or second time. Therefore the two TSM groups are hereafter called 'early-career breeders' and 'experienced breeders'. Model averaged apparent survival probability estimates were 0.534 (95\% CI [0.292, 0.760]) for early-career breeders and 0.675 (95\% CI [0.503, 0.810]) for experienced breeders (Figure 1; estimates based on models 1a, 2a, 5a and 7a, Table 2). Survival probability did not differ between males and females. The model averaged survival estimates were 0.533 (95\% CI [0.293, $0.758])$ in early-career and $0.669(95 \%$ CI $[0.485,0.812])$ in experienced males, while they were 0.555 (95\% CI [0.262, 0.814]) in early-career and 0.689 (95\% CI $[0.467,0.849])$ in experienced females (estimates based on all models, Table 2). Recapture probability was consistently explained by sex across all survival model structures (Tables 1 and 2). Model averaged recapture probability was higher for males $(0.496,95 \%$ CI $[0.270,0.724])$ than females $(0.207,95 \%$ CI $[0.065,0.493]$; estimates based on all models, Table 2).

In southern Finland, the variable subarea received the most support in explaining apparent survival of goshawks (Table 1) being included in the top six models (Table 3). Model averaged apparent survival probability was $0.715(95 \%$ CI $[0.442,0.888])$ in the Turku subarea and $0.534(95 \%$ CI $[0.382,0.680]$ ) in the Pori subarea (estimates based on models $1 \mathrm{~b}, 6 \mathrm{~b}, 8 \mathrm{~b}, 11 \mathrm{~b}, 14 \mathrm{~b}$ and 19b, Table 3). Differences in survival between males and females were small; model averaged estimates were 
$0.741(95 \%$ CI $[0.454,0.908])$ for males and 0.661 (95\% CI $[0.349,0.876])$ for females in Turku, and $0.555(95 \%$ CI $[0.389,0.709])$ for males and 0.458 (95\% CI $[0.235,0.700])$ for females in Pori (estimates based on models 1b, 2b, 4b-6b, 8b, 10b, 11b, 12b, 14b, 17b and 19b, Table 3). TSM effect was not supported (Table 1). Sex was the most important variable explaining recapture probability (Table 1). Model averaged recapture probability was 0.359 (95\% CI [0.208, 0.544]) for males and 0.249 (95\% CI [0.098, 0.504]) for females (estimates based on models $1 \mathrm{~b}-4 \mathrm{~b}, 6 \mathrm{~b}-10 \mathrm{~b}$, 14b, 16b-18b and 22b, Table 3).

\section{Site fidelity and territory turnover}

Both estimation approaches indicated high site fidelity in male goshawks in both northern (approach 1: 1.000, $\mathrm{n}=17$; approach 2: 0.909, $\mathrm{n}=22)$ and southern Finland (approach 1: 1.000, $\mathrm{n}=$ 19; approach 2: 0.966, $\mathrm{n}=29$; Figure 2a). Site fidelity was lower in females than in males in northern Finland (approach 1: 0.500, $\mathrm{n}=6$; approach 2: 0.615, $\mathrm{n}=13$; Table 4, Figure 2a), but not in southern Finland (approach 1: 0.900, $\mathrm{n}=10$; approach 2: 0.938, $\mathrm{n}=16$ ). Female site fidelity was also lower in northern Finland compared to southern Finland (Figure 2a), though not quite significantly so for the estimation approach 1 (Table 4).

Turnover rates of males were similar in northern (approach 1: 0.077, $\mathrm{n}=13$; approach 2: $0.560, \mathrm{n}=$ 25 ) and southern Finland (approach 1: 0.053, $\mathrm{n}=19$; approach 2: 0.314, $\mathrm{n}=35$; Table 4, Figure 2b). In northern Finland, turnover rate was higher in females (approach 1: 0.667, $\mathrm{n}=9$; approach 2: $0.789, \mathrm{n}=19$ ) than in males (Table 4, Figure $2 \mathrm{~b}$ ). Female turnover was also higher in northern Finland than in southern Finland (approach 1: 0.250, $\mathrm{n}=12$; approach 2: 0.400, $\mathrm{n}=25$; Table 4; Figure $2 \mathrm{~b}$ ), although the difference based on the approach 1 remained barely nonsignificant (Table 4). Overdispersion levels were acceptable in all models (residual deviance/df $\leq 1.313$ ). 


\section{Discussion}

291 We report the first apparent adult survival estimates based on mark-recapture data in goshawks 292 breeding close to their northern range limit. We found relatively low adult survival with no apparent 293 differences between northern and southern Finland or between sexes. Mean survival estimates for 294 different sexes and areas varied between 0.46 and 0.74 , a range which is at the low end reported in 295 previous mark-recapture or radio telemetry studies (0.62-0.86; Table 5). The survival estimates in 296 the Pori subarea in southern Finland (males 0.56, females 0.46) were especially low. The reason for 297 the very low (potentially unrealistically low) survival estimates in Pori is currently unknown. 298 Considering the size of goshawks ( $c a .1 \mathrm{~kg}$ ) they could be predicted to have a mean survival of 0.80 299 (Newton et al. 2016), higher than found in this study.

Recapture probabilities of goshawks were generally low, at maximum 0.50 , a problem also prevalent in previous studies (DeStefano et al. 1994, Kennedy 1997, Reynolds et al. 2004). Low recapture probabilities reflect the general difficulty of capturing goshawks. Especially females are usually less aggressive than males in attacking the eagle owl lure used in capture attempts. Higher breeding dispersal probability could also result to temporary emigration, and thus further explain the low recapture probabilities of females.

The relatively low adult survival estimates reflect either true survival or alternatively a higher degree of permanent emigration (Sandercock 2006). We used estimates of site fidelity and territory turnover to evaluate the possibility of permanent emigration. We found high site fidelity in males in both study areas (91-100\%) and in females in southern Finland (90-94\%) but lower in females in northern Finland (50-62\%). Turnover rates mirrored site fidelity being particularly high in females in northern Finland (67-79\%) compared to females in southern Finland (25-40\%) or males in 
overall (5-56\%). Turnover of females in northern Finland was also remarkably high in comparison to North American goshawk populations (males 23\%-25\%; females 16\%-30\%; Detrich \& Woodbridge 1994, Bechard et al. 2006, Reynolds \& Joy 2006). Site fidelity and turnover estimates are lacking for European goshawk populations, but Krüger (2005) noted that in female goshawks in Germany breeding dispersal was observed only twice (74 females followed) during the 30-year study period implying high site fidelity.

Overall, it appears that at least the apparent survival estimates of females in northern Finland were confounded with permanent emigration outside the study areas. In northern Finland, survival tended to be lower for early-career breeders $(53 \%)$ than for experienced breeders $(68 \%)$. Given the site fidelity and turnover estimates, permanent emigration could be the prevailing explanation for the very low early-career apparent survival for females, but the same explanation appears unlikely for males. If permanent emigration is the sole explanation for the low early-career survival rates, TSM effect could be expected to be stronger for females than for males. However, we did not initially fit any interaction models and thus could not observe the potential interactive effects between sex and TSM. Post hoc fitting of sex*TSM interaction model indicated that the TSM effect might be more pronounced in females (apparent survival estimates: 0.47 in early-career and 0.67 in experienced males, and 0.41 in early-career and 0.80 in experienced females; based on model S(sex*TSM)p(sex)). The sex*TSM interaction effect was nevertheless far from significant $(\beta=-$ $0.926,95 \%$ CI $[-4.012,2.161])$, probably due to the small sample size.

An alternative explanation for the low apparent early-career survival, and perhaps the more probable one regarding males, is that breeding is such a demanding task for the new recruits that many of them die during the next non-breeding season. In goshawks, the male is almost solely responsible for providing food for both the female and nestlings (Kenward 2006). As a result, males 
might be in too bad condition at the start of the potentially harsh winter conditions (cold weather, low prey availability, short day-length) to survive through to the next spring. Only the highest quality individuals may survive to breed in the next year, and in further years as suggested by the relatively higher apparent survival of experienced breeders. In addition, males probably benefit from holding the same territory year-round, because site familiarity should enhance their provisioning capabilities during breeding (Kenward 2006). That may hinder their possibilities for movements outside the territory even during the non-breeding season. Females may, in contrast, counter the difficult winter conditions by increasing their movement beyond the territory boundaries (e.g. in search of prey), and consequently they may also end up breeding in another territory. This could at least partly explain the lower site fidelity and higher turnover of females than males, especially in northern Finland where the winter conditions are even more challenging than in southern Finland (Pirinen et al. 2012). Nevertheless, we cannot exclude the possibility that also some male dispersal events resulted to permanent emigration, and thus to low apparent survival. Likewise, low female early-career survival could also partly reflect truly low survival.

Yet another explanation for the difference between the early-career (or individuals captured for the first time) and experienced breeders could be that individuals dispersed from the study area due to the capture and handling per se. However, for this to be the case, the same pattern could have been expected to appear also in southern Finland (capture method was identical in both areas), but TSM did not explain apparent survival there. Hence, the differences in apparent survival in northern Finland most likely reflect natural patterns.

In conclusion, apparent survival rates of goshawks in Finland were relatively low, and probably at least partly confounded with permanent emigration. Apparently the most reliable survival estimates were obtained for males, but even they were relatively low in comparison to previous studies. In 
364 northern Finland, females apparently exhibited frequent breeding dispersal, a previously 365 undiscovered behaviour in goshawks, despite having been frequently observed in birds in general 366 (e.g. Greenwood 1980, Pakanen et al. 2015). Both the low survival rates of males and high dispersal 367 propensity of females may be related to sex-specific roles in breeding and territorial behaviour as 368 well as to challenging environmental conditions during winter. In other raptors and owls adverse 369 weather conditions do affect survival (Francis \& Saurola 2004, Reichert et al. 2010, Franke et al. 370 2011), and in the goshawk harsh winters result in decreased breeding density in the next season 371 (Tornberg et al. 2013), potentially due to weather-related variation in survival. Further 372 investigations of weather effects on goshawk survival and dispersal propensity are warranted with 373 data spanning for longer time periods than in our study (Grosbois et al. 2008). 


\section{Acknowledgements}

376 We are thankful to Teemu Honkanen, and Jukka and Jouko Kivelä for collecting a considerable part 377 of the data of southern Finland. Comments from two anonymous reviewers improved the 378 manuscript. Funding was provided by the Natural History Society of Oulu (to JT) and the 379 Zoological Museum of the University of Oulu (to JT and RT).

380 


\section{References}

Akaike, H. 1974. New look at the statistical model identification. IEEE Transactions on Automatic Control AC 19: 716-723.

Andersen, D.E. 2007. Survey techniques. In Bird, D.M. \& Bildstein, K.L. (ed.) Raptor research and management techniques, Raptor Research Foundation, Hancock House Publishers, USA.

Bechard, M.J., Fairhurst, G.D. \& Kaltenecker, G.S. 2006. Occupancy, productivity, turnover, and dispersal of northern goshawks in portions of the northeastern Great Basin. Stud. Avian Biol. 31: 100-108.

BirdLife International. 2016. Accipiter gentilis. The IUCN Red List of Threatened Species 2016: e.T22695683A93522852. http://dx.doi.org/10.2305/IUCN.UK.20163.RLTS.T22695683A93522852.en. Downloaded on 19 December 2016.

Björklund, H., Valkama, J., Tomppo, E. \& Laaksonen, T. 2015. Habitat effects on the breeding performance of three forest-dwelling hawks. PLOS ONE 10: e0137877.

Boal, C.W., Andersen, D.E. \& Kennedy, P.L. 2003. Home range and residency status of northern goshawks breeding in Minnesota. Condor 105: 811-816.

Boal, C.W., Andersen, D.E. \& Kennedy, P.L. 2005. Productivity and mortality of northern goshawks in Minnesota. J. Raptor Res. 39: 222-228.

Brommer, J.E., Pietiäinen, H. \& Kolunen, H. 2002. Reproduction and survival in a variable environment: Ural owls (Strix uralensis) and the three-year vole cycle. Auk 119: 544-550.

Burnham, K.P. \& Anderson, D.R. 2002. Model selection and multimodel inference: a practical information-theoretic approach. 2nd edn. Springer, New York, USA.

Byholm, P., Burgas, D., Virtanen, T. \& Valkama, J. 2012. Competitive exclusion within the predator community influences the distribution of a threatened prey species. Ecology 93: 1802-1808. 
Byholm, P. \& Kekkonen, M. 2008. Food regulates reproduction differently in different habitats: experimental evidence in the goshawk. Ecology 89: 1696-1702.

Chakarov, N. \& Krüger, O. 2010. Mesopredator release by an emergent superpredator: a natural experiment of predation in a three level guild. PLOS ONE 5: e15229.

Collett, D. 2003. Modelling binary data. 2nd edn. Chapman \& Hall/ CRC, Florida, USA.

Cormack, R.M. 1964. Estimates of survival from the sighting of marked animals. Biometrika 51: 429-438.

DeStefano, S., Woodbridge, B. \& Detrich, P.J. 1994. Survival of northern goshawks in the southern Cascades of California. Stud. Avian Biol. 16: 133-136.

Detrich, P.J. \& Woodbridge, B. 1994. Territory fidelity, mate fidelity, and movements of colormarked northern goshawks in the southern Cascades of California. Stud. Avian Biol. 16: 130132.

Drennan, J.E. 2006. Northern goshawk food habits and goshawk prey species habitats. Stud. Avian Biol. 31: 198-218.

Francis, C.M. \& Saurola, P. 2004. Estimating components of variance in demographic parameters of Tawny Owls, Strix aluco. Animal Biodiversity and Conservation. 27.1: 489-502.

Franke, A., Therrien, J.-F., Descamps, S. \& Bêty, J. 2011. Climatic conditions during outward migration affect apparent survival of an arctic top predator, the peregrine falcon Falco peregrinus. J. Avian Biol. 42: 544-551.

Gaillard, J.-M., Festa-Bianchet, M., Yoccoz, N.G., Loison, A. \& Toïgo, C. 2000. Temporal variation in fitness components and population dynamics of large herbivores. Annu. Rev. Ecol. Syst. 31: 367-393.

Greenwood, P.J. 1980. Mating systems, philopatry and dispersal in birds and mammals. Anim. Behav. 28: 1140-1162. 
Gibson, S.Y., Van Der Marel, R.C. \& Starzomski, B.M. 2009. Climate change and conservation of leading-edge peripheral populations. Conserv. Biol. 23: 1369-1373.

Grosbois, V., Gimenez, O., Gaillard, J.-M., Pradel, R., Barbraud, C., Clobert, J., Møller, A.P. \& Weimerskirch, H. 2008. Assessing the impact of climate variation on survival in vertebrate populations. Biol. Rev. 83: 357-399.

Haas, C.A. 1998. Effects of prior nesting success on site fidelity and breeding dispersal: An experimental approach. Auk 115: 929-936.

Hakkarainen, H., Korpimäki, E., Koivunen, V. \& Ydenberg, R. 2002. Survival of male Tengmalm's owls under temporally varying food conditions. Oecologia 131: 83-88.

Hakkarainen, H., Mykrä, S., Kurki, S., Tornberg, R. \& Jungell, S. 2004. Competitive interactions among raptors in boreal forests. Oecologia 141: 420-424.

Haukioja, E. \& Haukioja, M. 1970. Mortality rates of Finnish and Swedish goshawks (Accipiter gentilis). Finnish Game Research 31: 13-20.

Heppell, S.S., Caswell, H. \& Crowder, L.B. 2000. Life histories and elasticity patterns: perturbation analysis for species with minimal demographic data. Ecology 81: 654-665.

Hoover, J.P. 2003. Decision rules for site fidelity in a migratory bird, the prothonotary warbler. Ecology 84: 416-430.

Jiménez-Franco, M.V., Martinez, J.E., Pagán I. \& Calvo, J.F. 2013 Factors determining territory fidelity in a migratory forest raptor, the Booted Eagle Hieraetus pennatus. J. Ornithol. 154: 311-318.

Jetz, W., Wilcove, D.S. \& Dobson, A.P. 2007. Projected impacts of climate and land-use change on the global diversity of birds. PLoS Biol. 5: 1211-1219.

Jolly, G.M. 1965. Explicit estimates from capture-recapture data with both death and immigrationstochastic model. Biometrika 52: 225-247. 
Karvonen, J., Orell, M., Rytkönen, S., Broggi, J. \& Belda, E. 2012. Population dynamics of an expanding passerine at the distribution margin. J. Avian Biol. 43: 102-108.

Kennedy, P.L. 1997. The northern goshawk (Accipiter gentilis atricapillus): Is there evidence of a population decline? J. Raptor Res. 31: 95-106.

Kenward, R.E. 2006. The goshawk. T \& A D Poyser, London, UK.

Kenward, R.E., Marcström, V. \& Karlbom, M. 1981. Goshawk winter ecology in Swedish pheasant habitats. J. Wildl. Manage. 45: 397-408.

Kenward, R.E., Marcström, V. \& Karlbom, M. 1999. Demographic estimates from radiotagging: Models of age-specific survival and breeding in the goshawk. J. Anim. Ecol. 68: $1020-1033$.

Krüger, O. 2005. Age at first breeding and fitness in goshawk Accipiter gentilis. J. Anim. Ecol. 74: $266-273$.

Krüger, O. 2007. Long-term demographic analysis in goshawk Accipiter gentilis: the role of density dependence and stochasticity. Oecologia 152: 459-471.

Lebreton, J.-D., Burnham, K.P., Clobert, J. \& Anderson, D.R. 1992. Modeling survival and testing biological hypotheses using marked animals: A unified approach with case studies. Ecol. Monogr. 62: 67-118.

Lima, S.T. 2009. Predators and the breeding bird: behavioral and reproductive flexibility under the risk of predation. Biol. Rev. 84: 485-513.

Michel, V.T., Jiménez-Franco, M.V., Naef-Daenzer, B. \& Grüebler, M.U. 2016. Intraguild predator drives forest edge avoidance of a mesopredator. Ecosphere 7: e01229.

Morris, W.F. \& Doak, D.F. 2002. Quantitative conservation biology: theory and practice of population viability analysis. Sinauer Associates Inc, Sunderland, USA. 
Morosinotto, C., Thomson, R.L. \& Korpimäki, E. 2010. Habitat selection as an antipredator behaviour in a multi-predator landscape: all enemies are not equal. J. Anim. Ecol. 79: 327333.

Mönkkönen, M., Husby, M., Tornberg, R., Helle, P. \& Thomson, R.L. 2007. Predation as a landscape effect: the trading off by prey species between predation risks and protection benefits. J. Anim. Ecol. 76: 619-629.

Newton, I., McGrady, M.J. \& Oli, M.K. 2016. A review of survival estimates for raptors and owls. Ibis 158: 227-248.

Norrdahl, K. \& Korpimäki, E. 2000. Do predators limit the abundance of alternative prey? Experiments with vole-eating avian and mammalian predators. Oikos 91: 528-540.

Pakanen, V.-M., Lampila, S., Arppe, H. \& Valkama, J. 2015. Estimating sex specific apparent survival and dispersal of Little Ringed Plovers (Charadrius dubius). Ornis Fennica 92: 172186.

Park, K.J., Graham, K.E., Calladine, J. \& Wernham, C.W. 2008. Impacts of birds of prey on gamebirds in the UK: a review. Ibis 150 (Suppl. 1): 9-26.

Penteriani, V. 2002. Goshawk nesting habitat in Europe and North America: A review. Ornis Fennica 79: 149-163.

Pirinen, P., Simola, H., Aalto, J., Kaukoranta, J-P., Karlsson, P. \& Ruuhela, R. 2012. Climatological statistics of Finland 1981-2010. Reports 2012: 1. Finnish Meteorological Institute. Helsinki, Finland. 96 pp.

Pradel, R., Hines, J.E., Lebreton, J.-D. \& Nichols, J.D. 1997. Capture-recapture survival models taking account of transients. Biometrics 53: 60-72. 
R Development Core Team. 2016. R: A language and environment for statistical computing. - R Foundation for Statistical Computing, Vienna, Austria. ISBN 3-900051-07-0, URL http://www.R-project.org/.

Rehm, E.M., Olivas, P., Stroud, J. \& Feeley, K.J. 2015. Losing your edge: climate change and the conservation value of range-edge populations. Ecol. Evol. 5: 4315-4326.

Reichert, B.E., Martin, J., Kendall, W.L., Cattau, C.E. \& Kitchens, W.M. 2010. Interactive effects of senescence and natural disturbance on the annual survival probabilities of snail kites. Oikos 119: 972-979.

Reynolds, R.T. \& Joy, S.M. 2006. Demography of northern goshawks in northern Arizona, 19911996. Stud. Avian Biol. 31: 63-74.

Reynolds, R.T., White, G.C., Joy, S.M. \& Mannan, R.W. 2004. Effects of radiotransmitters on northern goshawks: Do tailmounts lower survival of breeding males? J. Wildl. Manage. 68: $25-32$.

Saether, B.-E. \& Bakke, Ø. 2000. Avian life history variation and contribution of demographic traits to the population growth rate. Ecology 81: 642-653.

Sandercock, B.K. 2006. Estimation of demographic parameters from live encounter data: a summary review. J. Wildl. Manage. 70: 1504-1520.

Saurola, P., Valkama, J. \& Velmala, W. 2013. The Finnish Bird Ringing Atlas. Vol. 1. - Finnish Museum of Natural History and the Ministry of Environment, Helsinki.

Seber, G.A. 1965. A note on the multiple-recapture census. Biometrika 52: 249-259.

Sergio, F., Caro, T., Brown, D., Clucas, B., Hunter, J., Ketchum, J., McHugh, K. \& Hiraldo, F. 2008. Top predators as conservation tools: ecological rationale, assumptions, and efficacy. Annu. Rev. Ecol. Evol. Syst. 39: 1-19.

Sergio, F. \& Hiraldo, F. 2008. Intraguild predation in raptor assemblages: a review. Ibis 150 (Suppl. 1): 132-145. 
Sexton, J.P., McIntyre, P.J., Angert, A.L. \& Rice, K.J. 2009. Evolution and ecology of species range limits. Annu. Rev. Ecol. Evol. Syst. 40: 415-436.

Squires, J.R. \& Ruggiero, L.F. 1995. Winter movements of adult northern goshawks that nested in southcentral Wyoming. J. Raptor Res. 29: 5-9.

Steenhof, K. \& Newton, I. 2007. Assessing nesting success and productivity. In Bird, D.M. \& Bildstein, K.L. (ed.) Raptor research and management techniques, Raptor Research Foundation, Hancock House Publishers, USA.

Thomson, R.L., Forsman, J.T., Sardà-Palomera, F. \& Mönkkönen, M. 2006. Fear factor: prey habitat selection and its consequences in a predation risk landscape. Ecography 29: 507-514.

Tiainen, J., Mikkola-Roos, M., Below, A., Jukarainen, A., Lehikoinen, A., Lehtiniemi, T., Pessa, J., Rajasärkkä, A., Rintala, J., Sirkiä, P. \& Valkama, J. 2016. Suomen lintujen uhanalaisuus 2015 - The 2015 Red List of Finnish Bird Species. Ympäristöministeriö \& Suomen ympäristökeskus.

Tornberg, R. 1997. Prey selection of the goshawk Accipiter gentilis during the breeding season: The role of prey profitability and vulnerability. Ornis Fennica 74: 15-28.

Tornberg, R. 2001. Pattern of goshawk Accipiter gentilis predation on four forest grouse species in northern Finland. Wildlife Biol. 7: 245-256.

Tornberg, R. \& Colpaert, A. 2001. Survival, ranging, habitat choice and diet of the northern goshawk Accipiter gentilis during winter in northern Finland. Ibis 143: 41-50.

Tornberg, R., Lindén, A., Byholm, P., Ranta, E., Valkama, J., Helle, P. \& Lindén, H. 2013. Coupling in goshawk and grouse population dynamics in Finland. Oecologia 171: 863-872.

Tornberg, R., Rytkönen, S., Välimäki, P., Valkama, J. \& Helle, P. 2016. Northern goshawk (Accipiter gentilis) may improve black grouse breeding success. J. Ornithol. 157: 363-370. 
Underwood, J., White, C.M. \& Rodriguez, R.L. 2006. Winter movement and habitat use of northern goshawks breeding in Utah. Stud. Avian Biol. 31: 228-238.

Valkama, J., Korpimäki, E., Arroyo, B., Beja, P., Bretagnolle, V., Bro, E., Kenward, R., Mañosa, S., Redpath, S.M., Thirgood, S. \& Viñuela, J. 2005. Birds of prey as limiting factors of gamebird populations in Europe: a review. Biol. Rev. 80: 171-203.

Virkkala, R., Heikkinen, R.K., Leikola, N. \& Luoto, M. 2008. Projected large-scale range reductions of northern-boreal land bird species due to climate change. Biol. Conserv. 141: 1343-1353.

White, G.C. \& Burnham, K.P. 1999. Program MARK: Survival estimation from populations of marked animals. Bird Study 46: S120-S139.

White, G.C., Burnham, K.P. \& Anderson, D.R. 2001. Advanced features of Program Mark. - In: Field, R., Warren, R. J., Okarma, H. \& Sievert, P. R. (ed.) Wildlife, Land, and People: Priorities for the 21st Century. Proceedings of the Second International Wildlife Management Congress. The Wildlife Society, Bethesda, Maryland, USA, pp 368-377. 
562 Table 1. Relative importance of variables in explaining apparent survival and recapture probability of

563 Northern Goshawks in northern and southern Finland. The most important variables are in bold.

\begin{tabular}{|c|c|c|c|c|c|}
\hline Area & Parameter & Variable $^{\mathrm{a}}$ & $\begin{array}{c}\text { Sum of Akaike } \\
\text { weights }\end{array}$ & $\begin{array}{c}\text { Mean Akaike } \\
\text { weight }\end{array}$ & $\begin{array}{c}\text { Number of } \\
\text { models }\end{array}$ \\
\hline Northern & Survival & TSM & 0.531 & 0.133 & 4 \\
\hline \multirow[t]{4}{*}{ Finland } & probability & Sex & 0.307 & 0.077 & 4 \\
\hline & & Constant & 0.314 & 0.157 & 2 \\
\hline & Recapture & Sex & 0.866 & 0.217 & 4 \\
\hline & probability & Constant & 0.134 & 0.033 & 4 \\
\hline Southern & Survival & Subarea & 0.744 & 0.083 & 9 \\
\hline \multirow[t]{6}{*}{ Finland } & probability & TSM & 0.314 & 0.035 & 9 \\
\hline & & Sex & 0.405 & 0.045 & 9 \\
\hline & & Constant & 0.074 & 0.025 & 3 \\
\hline & Recapture & Subarea & 0.157 & 0.022 & 7 \\
\hline & probability & Sex & 0.519 & 0.074 & 7 \\
\hline & & Constant & 0.324 & 0.046 & 7 \\
\hline
\end{tabular}

$564{ }^{a}$ TSM = time since marking effect (early-career breeders vs. experienced breeders); Sex = the sex effect (males vs.

565 females); Subarea $=$ the subarea effect within the SF study area (Turku vs. Pori); Constant $=$ survival/recapture

566 probability constant between individuals.

567 
568 Table 2. Models of apparent adult survival of the Northern Goshawk in northern Finland.

\begin{tabular}{lccccc}
\hline & & & Akaike & Model & \\
Model $^{\mathbf{a}}$ & QAICc & NQAICc & weight & likelihood & Parameters \\
\hline 1a. S(TSM)p(Sex) & 177.648 & 0.00 & 0.323 & 1.000 & 4 \\
2a. S(Constant)p(Sex) & 177.903 & 0.26 & 0.285 & 0.880 & 3 \\
3a. S(Sex)p(Sex) & 179.363 & 1.72 & 0.137 & 0.424 & 4 \\
4a. S(Sex+TSM)p(Sex) & 179.608 & 1.96 & 0.121 & 0.375 & 5 \\
5a. S(TSM)p(Constant) & 181.172 & 3.52 & 0.056 & 0.172 & 3 \\
6a. S(Sex+TSM)p(Constant) & 182.319 & 4.67 & 0.031 & 0.097 & 4 \\
7a. S(Constant)p(Constant) & 182.444 & 4.80 & 0.029 & 0.091 & 2 \\
& & & & & 3
\end{tabular}

$569{ }^{a} \mathrm{~S}()$ denotes the survival and $\mathrm{p}()$ the recapture model structure with the explanatory variables in parentheses. Sex $=$ the 570 sex effect (males vs. females); TSM = time since marking effect (early-career breeders vs. experienced breeders);

571 Constant $=$ survival $/$ recapture probability constant between individuals.

572 
573 Table 3. Models of apparent adult survival of the Northern Goshawk in southern Finland.

\begin{tabular}{|c|c|c|c|c|c|}
\hline & & & Akaike & Model & \\
\hline Model $^{a}$ & AICc & $\Delta \mathrm{AICc}$ & weight & likelihood & Parameters \\
\hline 1b. S(Subarea)p(Sex) & 246.365 & 0.00 & 0.171 & 1.000 & 4 \\
\hline 2b. S(Subarea+Sex)p(Constant) & 246.600 & 0.24 & 0.152 & 0.889 & 4 \\
\hline 3b. S(Subarea+TSM)p(Sex) & 246.635 & 0.27 & 0.149 & 0.874 & 5 \\
\hline 4b. S(Subarea + Sex $) p($ Sex $)$ & 248.039 & 1.67 & 0.074 & 0.433 & 5 \\
\hline 5b. S(Subarea+Sex)p(Subarea) & 248.493 & 2.13 & 0.059 & 0.345 & 5 \\
\hline 6b. S(Subarea)p(Constant) & 248.529 & 2.16 & 0.058 & 0.339 & 3 \\
\hline 7b. S(TSM)p(Sex) & 249.128 & 2.76 & 0.043 & 0.251 & 4 \\
\hline 8b. S(Constant)p(Sex) & 249.163 & 2.80 & 0.042 & 0.247 & 3 \\
\hline 9b. S(Subarea+TSM)p(Constant) & 249.581 & 3.22 & 0.034 & 0.200 & 4 \\
\hline 10b. S(Sex)p(Constant) & 249.934 & 3.57 & 0.029 & 0.168 & 3 \\
\hline 11b. S(Subarea)p(Subarea) & 250.497 & 4.13 & 0.022 & 0.127 & 4 \\
\hline 12b. S(Sex)p(Subarea) & 250.553 & 4.19 & 0.021 & 0.123 & 4 \\
\hline \multicolumn{6}{|l|}{ 13b. S(Subarea+Sex+TSM) } \\
\hline $\mathrm{p}($ Subarea + Sex $)$ & 250.768 & 4.40 & 0.019 & 0.111 & 7 \\
\hline 14b. S(Constant)p(Constant) & 250.895 & 4.53 & 0.018 & 0.104 & 2 \\
\hline 15b. S(Sex+TSM)p(Subarea) & 251.085 & 4.72 & 0.016 & 0.094 & 5 \\
\hline 16b. S(Sex+TSM)p(Constant) & 251.088 & 4.72 & 0.016 & 0.094 & 4 \\
\hline 17b. S(Sex)p(Sex) & 251.105 & 4.74 & 0.016 & 0.094 & 4 \\
\hline 18b. S(Sex+TSM)p(Sex) & 251.267 & 4.90 & 0.015 & 0.086 & 5 \\
\hline 19b. S(Constant)p(Subarea) & 251.576 & 5.21 & 0.013 & 0.074 & 3 \\
\hline 20b. S(TSM)p(Subarea) & 251.630 & 5.26 & 0.012 & 0.072 & 4 \\
\hline 21b. S(Subarea+TSM)p(Subarea) & 251.719 & 5.35 & 0.012 & 0.069 & 5 \\
\hline 22b. S(TSM)p(Constant) & 251.791 & 5.43 & 0.011 & 0.066 & 3 \\
\hline
\end{tabular}


$574{ }^{a} \mathrm{~S}()$ denotes the survival and $\mathrm{p}()$ the recapture model structure with the explanatory variables in parentheses. Subarea $=$

575 the subarea effect within the SF study area (Turku vs. Pori); Sex = the sex effect (males vs. females); TSM = time since

576 marking effect (early-career breeders vs. experienced breeders); Constant = no variation in survival/recapture

577 probability.

578

579 
Table 4. Model statistics of site fidelity and territory turnover rate analyses. Calculation of the response variables were based on either captures in successive years (approach 1) or all successive captures regardless of the number of years between the captures (approach 2), but controlling for the variable number of years

583 between the captures (parameter 'Years').

\begin{tabular}{|c|c|c|c|c|}
\hline Response variable & Group & Parameter & $\chi_{D f=1}^{2}$ & p-value \\
\hline Site fidelity & Males & Area & 0.000 & 1.000 \\
\hline \multirow[t]{3}{*}{ Approach 1} & Females & Area & 3.175 & 0.075 \\
\hline & Northern Finland & Sex & 9.494 & 0.002 \\
\hline & Southern Finland & Sex & 2.198 & 0.138 \\
\hline Site fidelity & Males & Area & 0.514 & 0.473 \\
\hline \multirow[t]{7}{*}{ Approach 2} & & Years & 1.093 & 0.296 \\
\hline & Females & Area & 5.994 & 0.014 \\
\hline & & Years & 2.013 & 0.156 \\
\hline & Northern Finland & Sex & 4.877 & 0.027 \\
\hline & & Years & 0.576 & 0.448 \\
\hline & Southern Finland & Sex & 0.209 & 0.648 \\
\hline & & Years & 0.038 & 0.845 \\
\hline Turnover & Males & Area & 0.076 & 0.782 \\
\hline \multirow[t]{3}{*}{ Approach 1} & Females & Area & 3.729 & 0.053 \\
\hline & Northern Finland & Sex & 9.013 & 0.003 \\
\hline & Southern Finland & Sex & 2.510 & 0.113 \\
\hline Turnover & Males & Area & 1.421 & 0.233 \\
\hline \multirow[t]{6}{*}{ Approach 2} & & Years & 50.462 & $<0.001$ \\
\hline & Females & Area & 7.253 & 0.007 \\
\hline & & Years & 3.261 & 0.071 \\
\hline & Northern Finland & Sex & 5.819 & 0.016 \\
\hline & & Years & 18.272 & $<0.001$ \\
\hline & Southern Finland & Sex & 0.100 & 0.752 \\
\hline
\end{tabular}


586 Table 5. Survival probabilities estimated for different populations of the Northern Goshawk.

\begin{tabular}{lccccl}
\hline Location & Survival $^{\mathrm{a}}$ & Method $^{\mathrm{d}}$ & Years & n & Reference \\
\hline Europe & & & & & \\
Gotland, Sweden & $0.79-0.83$ & $\mathrm{RT}$ & $1980-1984$ & 78 & Kenward et al. 1999 \\
Germany & $0.62-0.79^{\mathrm{b}}$ & $\mathrm{CMR}^{\mathrm{e}}$ & $1980-2003$ & 74 & Krüger 2005 \\
Oulu, Finland & $0.80^{\mathrm{c}}$ & $\mathrm{RT}$ & $1991-1994$ & 19 & Tornberg and Colpaert 2001 \\
Oulu, Finland & $0.53-0.68$ & $\mathrm{CMR}$ & $2003-2012$ & 91 & This study \\
Turku, Finland & 0.72 & CMR & $2005-2011$ & 40 & This study \\
Pori, Finland & 0.53 & CMR & $2005-2011$ & 80 & This study \\
\hline
\end{tabular}

\section{North America}

New Mexico, USA $\quad 0.86 \quad$ CMR $\quad 1983-1995 \quad 45 \quad$ Kennedy 1997

Arizona, USA $\quad 0.75 \quad$ CMR $\quad 1991-2000 \quad 265 \quad$ Reynolds et al. 2004

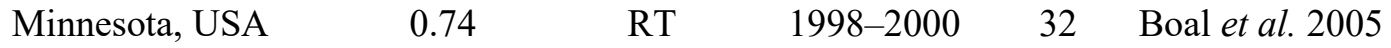

$587{ }^{a}$ Survival probabilities did not differ between males and females in any of the studies (Kennedy 1997, Kenward et al. 588 1999, Reynolds et al. 2004, this study), or they were not tested (Tornberg and Colpaert 2001, Boal et al. 2005).

589 Therefore, overall survival estimates are reported.

$590 \quad{ }^{b}$ Estimate based on females only.

$591{ }^{\mathrm{c}}$ Estimate derived only for the five winter months (November-March)

$592{ }^{\mathrm{d}} \mathrm{RT}=$ radio telemetry, $\mathrm{CMR}=$ capture-mark-recapture(resight)

$593{ }^{\mathrm{e}}$ Birds were not physically captured, but the identification of individuals was based on shed feathers. 


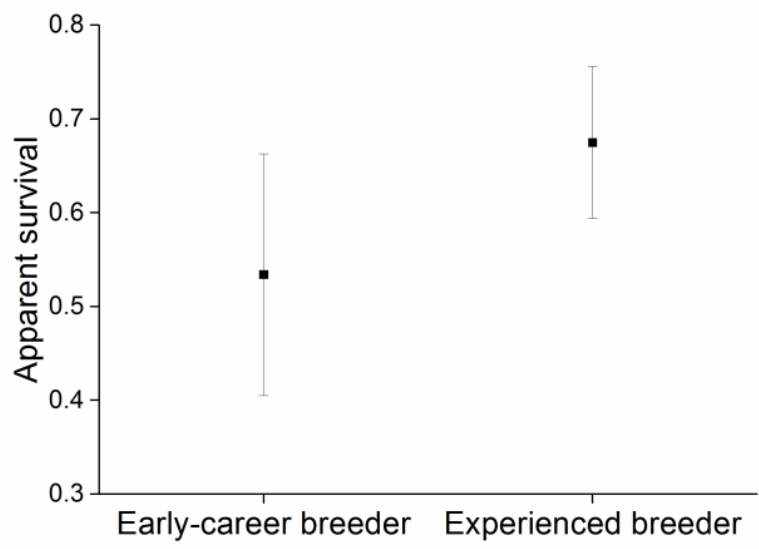

597 Figure 1. Apparent survival probability of early-career breeders and experienced breeders in northern $598 \quad$ Finland (model averaged estimates \pm unconditional SEs).

599
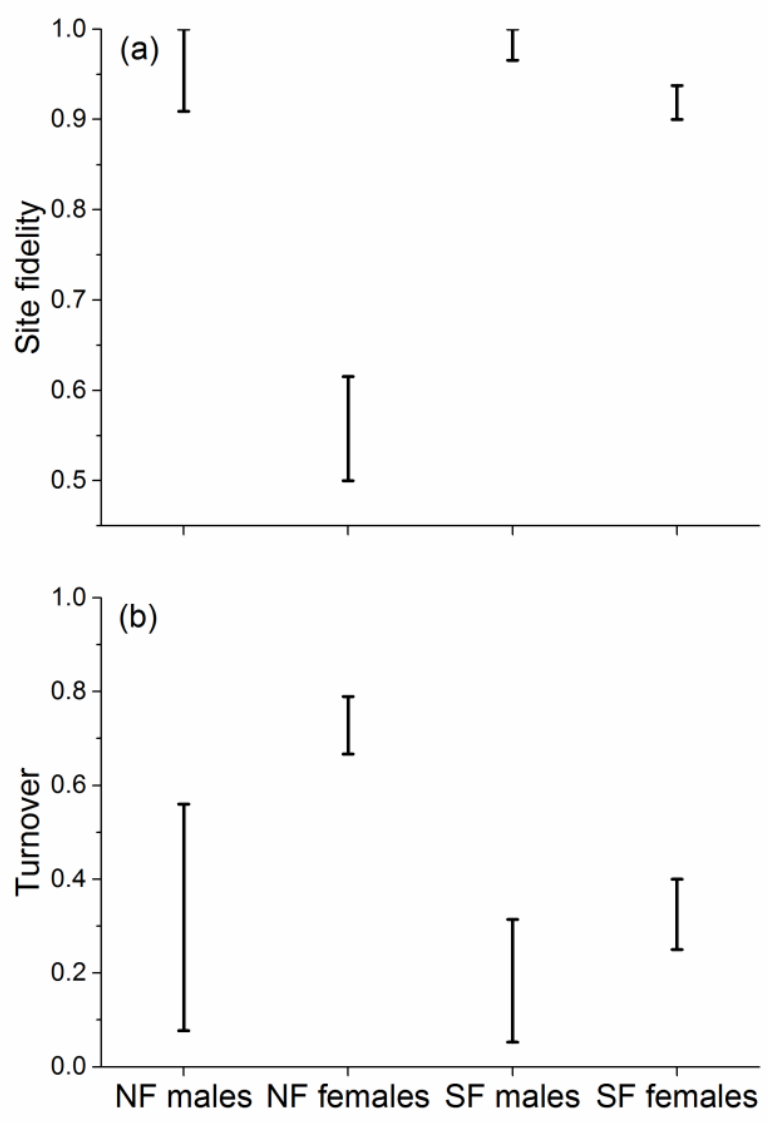

601 Figure 2. Ranges of (a) site fidelity and (b) territory turnover rate estimates of male and female Northern 602 Goshawks in northern (NF) and southern (SF) Finland. 